\title{
Analysis of the Conjugate Heat Transfer in a Multi-Layer Wall Including an Air Layer
}

\author{
Armando Gallegos M., Christian Violante C., \\ José A. Balderas B., Víctor H. Rangel H. and José M. Belman F. \\ Department of Mechanical Engineering, University of Guanajuato, Guanajuato, \\ México
}

\section{Introduction}

At present the design of efficient furnace is fundamental to reducing the fuel consumption and the heat losses, as well as to diminish the environment impact due to the use of the hydrocarbons. To reduce the heat losses in small industrial furnaces, a multi-layer wall that includes an air layer, which acts like a thermal insulator, can be applied. This concept is applied in the insulating of enclosures or spaces constructed with perforated bricks to maintain the comfort, without using additional thermal insulator in the walls (Lacarrière et al., 2003; Lacarrière et al., 2006). Besides it has been used to increase the insulating effect in the windows of the enclosures (Aydin, 2000; Aydin, 2006). Nevertheless, the thickness of the air layer must be such that it does not allow the movement of the air. Free movement of the air is favorable to the formation of cellular flow patterns that increase the heat transfer coefficient, provoking natural convection heat transfer through the air layer, reducing the insulating capacity of the multi-layer wall due to the transition from conduction to convection regime. A way to diminish the effect of the natural convection is to apply vertical partitions to provide a larger total thickness in the air layer (Samboua et al., 2008). In Mexico there are industrial furnaces used to bake ceramics, in which the heat losses through the walls are significant, representing an important cost of production. In order to understand this problem, a previous study of the conjugate heat transfer was made of a multi-layer wall (Balderas et al., 2007), where it was observed that a critical thickness exists which identified the beginning of the natural convection process in the air layer. This same result was obtained by Aydin (Aydin, 2006) in the analysis of the conjugate heat transfer through a double pane window, where the effect of the climatic conditions was studied. For the analysis of the multi-layer wall a model applying the volume finite method (Patankar, 1980) was developed. This numerical model, using computational fluid dynamics (Fluent 6.2.16, 2007), allowed to study the natural convection in the air layer with different thicknesses, identifying that one which provides major insulating effect in the wall.

\section{Model of the multi-layer wall}

Industrial furnaces have diverse forms according to the application. The furnace consists of a space limited by refractory walls which are thermally isolated. In the furnace used to bake ceramics the forms are diverse, depending on the operating conditions of the furnace, also, 
the thermal isolation is inadequate requiring redesign of the furnace to adapt it to the conditions of production and operation (U.S.A. Department of Energy, 2004) and to obtain the maximum efficiency of the process. To solve this problem a multi-layer wall including an air layer to reduce the heat losses and improving the furnace efficiency is proposed.

The Figure 1(a) shows the configuration of the multi-layer wall, where the thickness of the air layer, $L$, varies while the height of the wall is constant. The materials of the multi-layer wall and $\mathrm{H}$ are defined according to the requirements of the furnace. When the thickness of the air layer is increased, some partitions are applied to obtain the insulating effect in the wall. The Figure 1(b) shows the air layer with partitions. The thickness of the air layer, $L$, varies from 0 to $10 \mathrm{~cm}$. In each case, the heat flow towards the outside of the furnace wall is calculated to identify the thickness that allows the minimal heat losses, defined as the optimal air layer thickness.

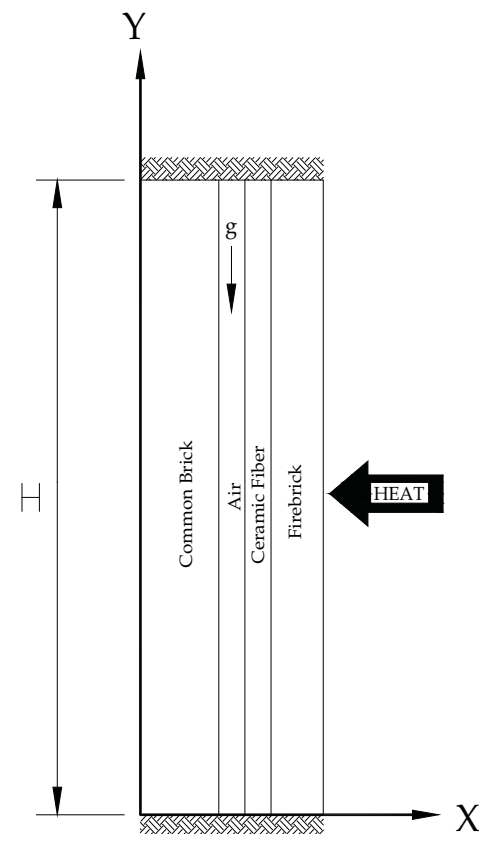

(a)

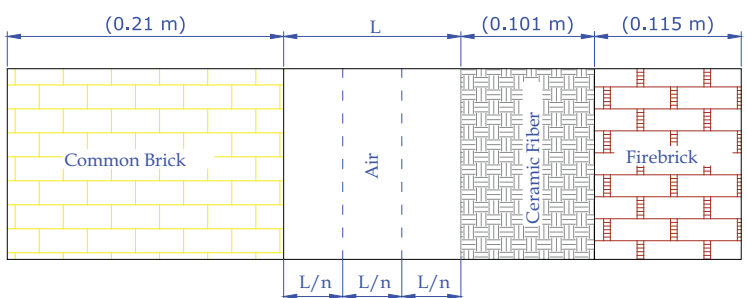

(b)

Fig. 1. Composition of the multi-layer wall.

When the thickness of the air layer is increased, the natural convection leads to the formation of cellular flow patterns that increase the heat transfer coefficient and reduce the isolation capacity (Ganguli et al., 2009). Therefore an air layer with vertical partitions in order to maintain the maximum insulation is proposed. In this air layer, each partition has a thickness near the optimal thickness, which is obtained from the analysis of the conduction and convection heat transfer. According to this analysis, a multi-layer wall with 8 and $10 \mathrm{~cm}$ of thickness and two, three or four partitions is applied. The configuration of the air layer with partitions is identified according to the following nomenclature. 


$$
\underbrace{L}_{\begin{array}{c}
\text { thickness of } \\
\text { the air layer }
\end{array}} \underbrace{[n]}_{\begin{array}{c}
\text { partitions of } \\
\text { the air layer }
\end{array}}
$$

where $n$ is the partitions number and $L$ is the thickness of the air layer.

\section{Mathematical formulation}

The analysis of the multi-layer wall considers the solution of the conjugate heat transfer in steady state between the solid and the air layer in a vertical cavity, which was obtained by CFD (FLUENT®), where a model in two dimensions with constant properties except density is applied, the Boussinesq and non- Boussinesq approximation (Darbandi \& Hosseinizadeh, 2007) for the buoyancy effects were used. The work of compressibility and the terms of viscous dissipation in the energy equation were neglected. The thermal radiation within the air layer was neglected. In the non-Boussinesq approximation, the fluid is considered as an ideal gas. The governing equations for the model are:

\section{Continuity equation}

$$
\frac{\partial u_{x}}{\partial x}+\frac{\partial u_{y}}{\partial y}=0
$$

\section{Momentum equations}

component $\mathrm{x}$ :

$$
u_{x} \frac{\partial u_{x}}{\partial x}+u_{y} \frac{\partial u_{x}}{\partial y}=v\left(\frac{\partial^{2} u_{x}}{\partial x^{2}}+\frac{\partial^{2} u_{x}}{\partial y^{2}}\right)
$$

component y:

$$
u_{x} \frac{\partial u_{y}}{\partial x}+u_{y} \frac{\partial u_{y}}{\partial y}=-\frac{\partial p}{\partial y}+v\left(\frac{\partial^{2} u_{y}}{\partial x^{2}}+\frac{\partial^{2} u_{y}}{\partial y^{2}}\right)+\rho g_{y}
$$

momentum equation with Boussinesq approximation

$$
u_{x} \frac{\partial u_{y}}{\partial x}+u_{y} \frac{\partial u_{y}}{\partial y}=g_{y} \beta\left(T-T_{0}\right)+v\left(\frac{\partial^{2} u_{y}}{\partial x^{2}}+\frac{\partial^{2} u_{y}}{\partial y^{2}}\right)
$$

\section{Energy equation}

$$
u_{x} \frac{\partial T}{\partial x}+u_{y} \frac{\partial T}{\partial y}=\alpha\left(\frac{\partial^{2} T}{\partial x^{2}}+\frac{\partial^{2} T}{\partial y^{2}}\right)
$$

the pressure gradient in the momentum equation in component $\mathrm{x}$ is not considered due to the small space between the vertical walls. The velocity in $x$ direction is important only in the top and bottom of the cavity due to the cellular pattern forms by the natural convection (Violante, 2009). 


\subsection{Density model}

According to the conditions of the problem, is necessary to apply a model of density. The first model applied was the Boussinesq approximation, where the difference of density is expressed in terms of the volumetric thermal expansion coefficient and the temperature difference. For this approximation, the momentum equation in $y$ is expressed by equation 5 , where the buoyancy effect depends only on the temperature. Nevertheless, this approximation is only valid for small temperature differences (Darbandi \& Hosseinizadeh, 2007). According to the temperature difference in the vertical cavity, it could be possible to use the ideal gas model to calculate the density in the air layer. Therefore, a model where the density is a function of the temperature applied to the problems of natural convection in vertical cavities subject to different side-wall temperatures (Darbandi \& Hosseinizadeh, 2007) is:

$$
\rho=\frac{P_{o p}}{\frac{R}{M_{w}} T}
$$

\subsection{Boundary onditions and heat flux}

The temperature used in baking of ceramics is between $1123 \mathrm{~K}\left(850^{\circ} \mathrm{C}\right)$ and $1173 \mathrm{~K}\left(900{ }^{\circ} \mathrm{C}\right)$, and the outside temperature of the furnace may be $300 \mathrm{~K}\left(27^{\circ} \mathrm{C}\right)$. Then, the boundary conditions are: bottom and top adiabatic boundary, left and right isothermal boundary and no-slip condition in the walls (including the partitions). In the solid-gas interface, the temperature and the heat flux must be continuous. The solution can be obtained for laminar flow; this consideration is contained in the Rayleigh number and the aspect ratio, whose ranges are $1000<\mathrm{Ra}_{\mathrm{L}}<10^{7}$ and $10<\mathrm{AR}(\mathrm{H} / \mathrm{L})<110$ are applied (Ganguli et al., 2009). The Rayleigh number for thin vertical cavities is defined as (Ganguli et al., 2009):

$$
10^{3}<R a_{L}=\frac{g \beta\left(T_{i}-T_{0}\right) L^{3}}{v \alpha}<10^{7}
$$

To determine the heat losses, the heat flux through the multi-layer wall is calculated by applying the following equation:

$$
q^{\prime \prime}=\frac{T_{i}-T_{o}}{\frac{l_{1}}{k_{\text {brick }}}+\frac{l_{2}}{k_{\text {iso }}}+\frac{l_{3}}{k_{\text {firebrick }}}+\frac{L}{k_{\text {eff }}}}
$$

where $l$ 's is the thickness of each material used in the wall and $k_{\text {eff }}$ is the effective conductivity obtained from the combination of the conduction and natural convection effects present in the air layer, which is define as:

$$
\mathrm{k}_{\text {eff }}=\mathrm{k}_{\text {air }} \overline{\mathrm{Nu}_{\mathrm{y}}}
$$

where the average Nusselt number is related to the average of heat transfer coefficient in the vertical cavity, which is obtained numerically,

$$
\overline{\mathrm{Nu}_{\mathrm{y}}}=\frac{\overline{\mathrm{h}} \mathrm{H}}{\mathrm{k}_{\mathrm{air}}}
$$




\section{Results and discussion}

The results were obtained for a multi-layer wall where the inside temperature, $\mathrm{T}_{i}$, of the furnace is $1173 \mathrm{~K}\left(900^{\circ} \mathrm{C}\right)$ and the outside temperature, $\mathrm{T}_{\mathrm{o}}$, is $300 \mathrm{~K}\left(27^{\circ} \mathrm{C}\right)$. The multi-layer wall is formed by four different materials; see Figure 1(b), whose properties are showed in the Table 1 (Incropera \& DeWitt, 1996).

\begin{tabular}{|c|c|c|c|c|c|}
\hline \multirow{2}{*}{$\frac{\text { Common Brick }}{\rho_{c b}}$} & \multicolumn{5}{|c|}{ Firebrick } \\
\hline & 1920 & $\mathrm{~kg} / \mathrm{m}^{3}$ & $\rho_{f b}$ & 2050 & $\mathrm{~kg} / \mathrm{m}^{3}$ \\
\hline$C_{p_{-} c b}$ & 835 & $\mathrm{~J} / \mathrm{kg} \mathrm{K}$ & $C_{p_{-} f b}$ & 960 & $\mathrm{~J} / \mathrm{kg} \mathrm{K}$ \\
\hline$k_{c b}$ & 0.72 & $\mathrm{~W} / \mathrm{m} \mathrm{K}$ & $k_{f b}$ & 1.1 & $\mathrm{~W} / \mathrm{m} \mathrm{K}$ \\
\hline \multicolumn{3}{|l|}{ Ceramic Fiber } & \multicolumn{3}{|c|}{ Air (750 K) } \\
\hline$\rho_{c f}$ & 32 & $\mathrm{~kg} / \mathrm{m}^{3}$ & $\rho_{a i r}$ & 0.4880 & $\mathrm{~kg} / \mathrm{m}^{3}$ \\
\hline$C_{p_{-} c f}$ & 835 & $\mathrm{~J} / \mathrm{kg} \mathrm{K}$ & $C_{p_{-} a i r}$ & 1081 & $\mathrm{~J} / \mathrm{kg} \mathrm{K}$ \\
\hline \multirow[t]{2}{*}{$k_{c f}$} & 0.22 & $\mathrm{~W} / \mathrm{m} \mathrm{K}$ & $k_{\text {air }}$ & 0.05298 & $\mathrm{~W} / \mathrm{m} \mathrm{K}$ \\
\hline & & & $\begin{array}{l}\mu_{\text {air }} \\
\alpha_{\text {air }}\end{array}$ & $\begin{array}{c}3.415 \times 10^{-5} \\
100.4 \times 10^{-6}\end{array}$ & $\begin{array}{c}\mathrm{kg} / \mathrm{m} \mathrm{s} \\
\mathrm{m}^{2} / \mathrm{s}\end{array}$ \\
\hline
\end{tabular}

Table 1. Properties of the materials in the multi-layer wall.

According to the properties of the fluid and assuming the film temperature of $750 \mathrm{~K}$, the maximum Rayleigh number is $R a_{L}=1.37 \times 10^{6}$, this value is related to the range of the equation (8), where the laminar flow governs the movement of the fluid. In order to quantify the natural convection, an analysis with both models of the density was done. For the model using the approach of Boussinesq, the equation of momentum in the $y$ direction is equation (5). In the second model with no-Boussinesq approximation, the equations (4) and (7) are applied, where the pressure changes inside the vertical cavity are neglected. The results obtained with both density models are showed in the Table 2, where the ideal gas model is used to analyze the conjugate heat transfer through the multi-layer wall because the Boussinesq approximation fails to predict the correct behavior of the natural convection when the temperature gradient is large (Darbandi \& Hosseinizadeh, 2007).

\begin{tabular}{ccc}
\hline Configuration & \multicolumn{1}{c}{ Heat flux $(\mathbf{W} / \mathbf{m} \mathbf{2})$} & \\
\cline { 2 - 3 } & Boussinesq approximation & Ideal gas model \\
\hline $8[1]$ & 621.31 & 715.37 \\
$8[2]$ & 463.94 & 565.86 \\
$8[3]$ & 423.10 & 465.49 \\
$8[4]$ & 463.29 & 429.57 \\
$10[1]$ & 629.31 & 715.37 \\
$10[2]$ & 468.28 & 576.42 \\
$10[3]$ & 389.91 & 470.07 \\
$10[4]$ & 458.80 & $\mathbf{4 0 0 . 8 4}$ \\
\hline
\end{tabular}

Table 2. Heat flux to Boussinesq and ideal gas model. 
The Figure 2 shows the heat flux by conduction and convection through the air layer for different thickness, obtained from equation (9). The conduction heat flux curve shows the insulating effect of the air layer without movement, with the Nusselt number equal to unity, where the heat losses through the multilayer wall continuously decrease for any thickness. The natural convection heat flux curve shows an asymptotic behavior with a constant minimal heat flux, the natural convection heat is produced by cellular flow patterns inside the air layer where the Nusselt number increases. The minimal heat flux is present in thicknesses greater than $3 \mathrm{~cm}$, identifying this value as the optimal thickness to maintain the insulating capacity of the air layer inside the multi-layer wall.

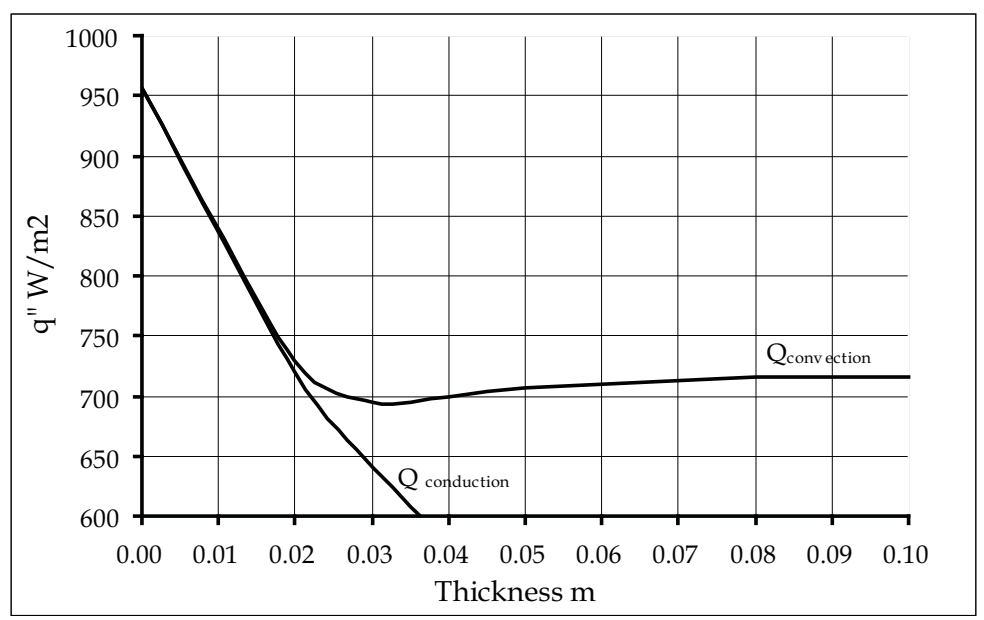

Fig. 2. Heat flow through the air layer.

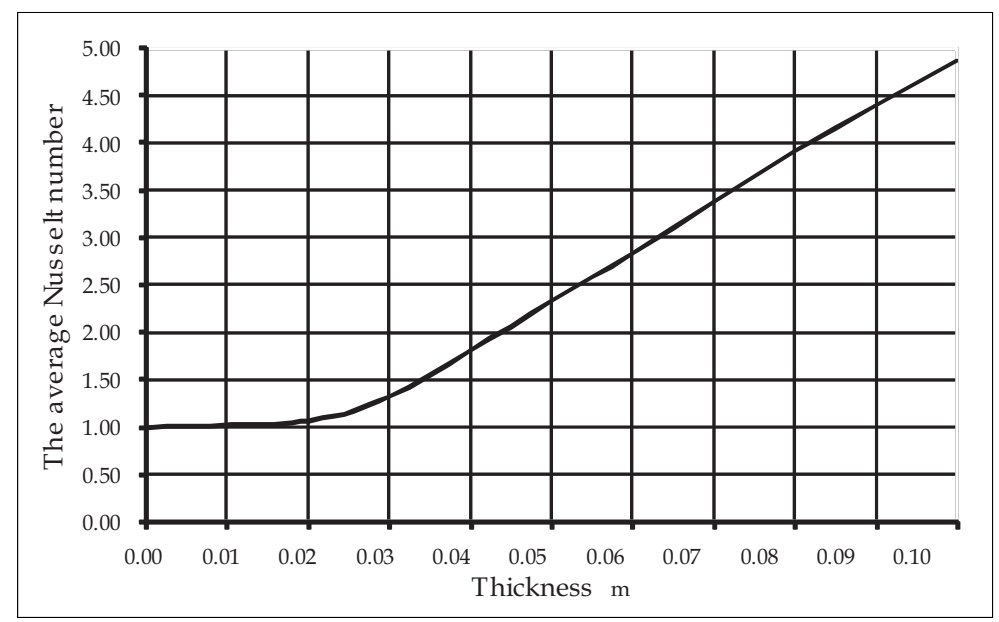

Fig. 3. Average Nusselt number in the air layer. 
The average Nusselt number for each of the air layer thickness is showed in the Figure 3. For values below the optimal thickness only heat transfer by conduction is presented and the Nusselt number is equal to the unit. In agreement with equation (10), the effective conductivity is equal to the conductivity of the air. When $L>0.02 \mathrm{~m}$ the Nusselt number is bigger than unity, this result corresponds to the heat transfer by natural convection, where the cellular flow patterns produces an increase in the heat transfer coefficient due to the temperature gradient applied.

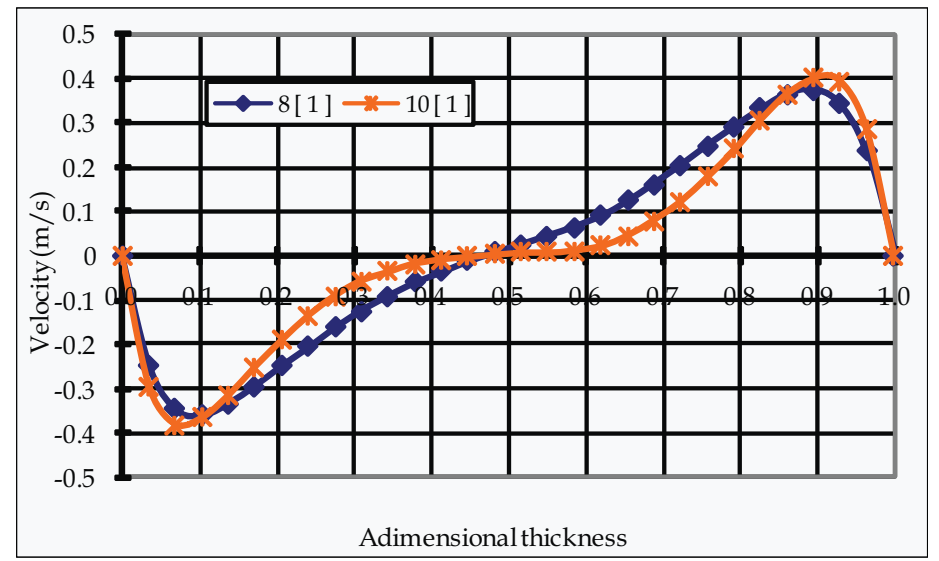

(a)

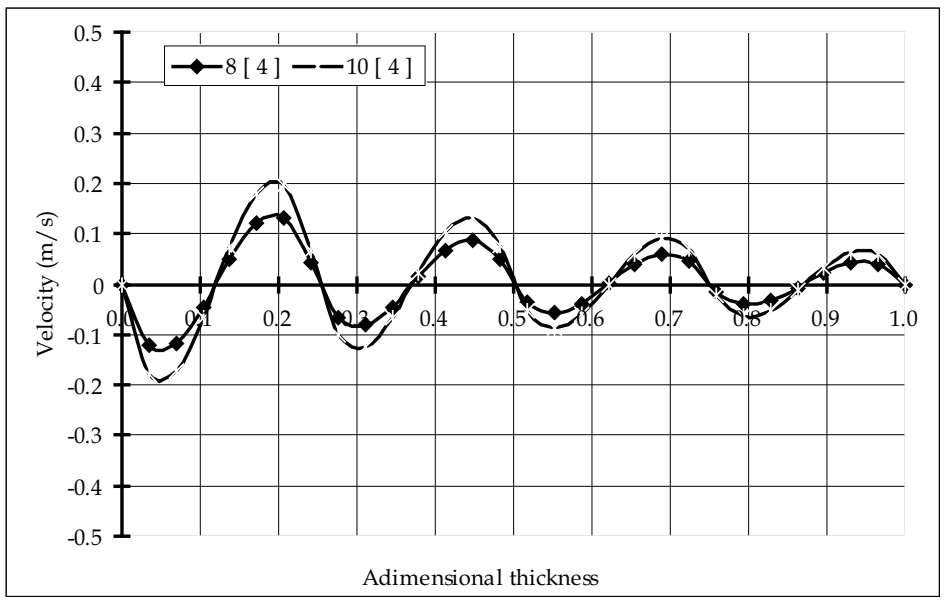

(b)

Fig. 4. Velocity profile in the air layer: (a) without partitions and (b) with four partitions.

After the optimal thickness has been determined, new thicknesses of the air layer are introduced to reduce the heat losses through multi-layer wall. These new configurations correspond to the thicknesses of 8 and $10 \mathrm{~cm}$, each one with 2, 3 or 4 partitions. In each configuration the velocity profile was determined, in order to see the behavior of the cellular patterns of the air inside the cavity. The Figure 4(a) shows the velocity profiles in the vertical 
direction in the air layer for the configurations 8 [1] and 10 [1]. According to equation (8) these configurations correspond to the air layer without partitions, where the velocity is greater near the vertical walls and practically zero in the center of the air layer, according to the unicellular flow pattern. For the same thicknesses, but with four partitions, 8 [4] and 10 [4], the velocity, Figure 4(b), shows a reduction in its values where the greatest value is near to the hottest wall, which indicates that the heat flux by natural convection through the multi-layer wall it is falling. In all the configurations a unicellular flow pattern is present.

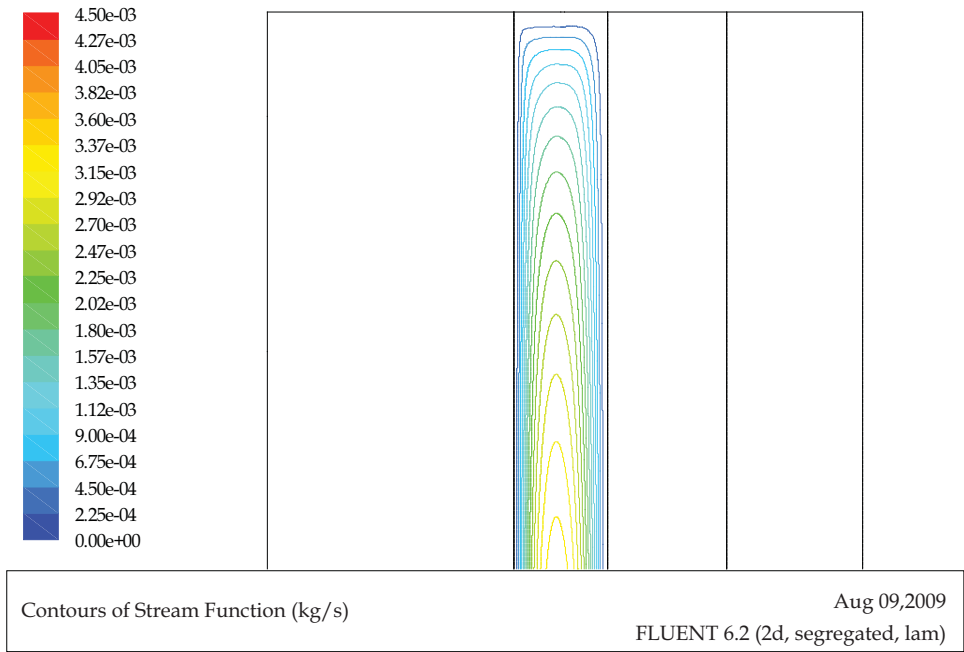

(a)

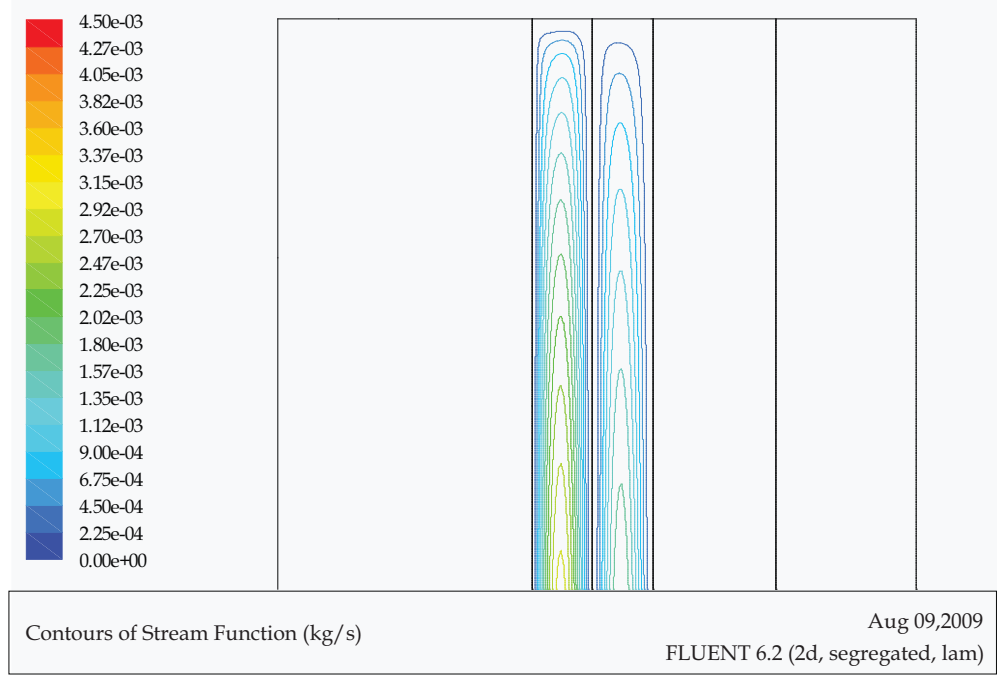

(b)

Fig. 5. (a) and (b) Streamlines in the air layer. 


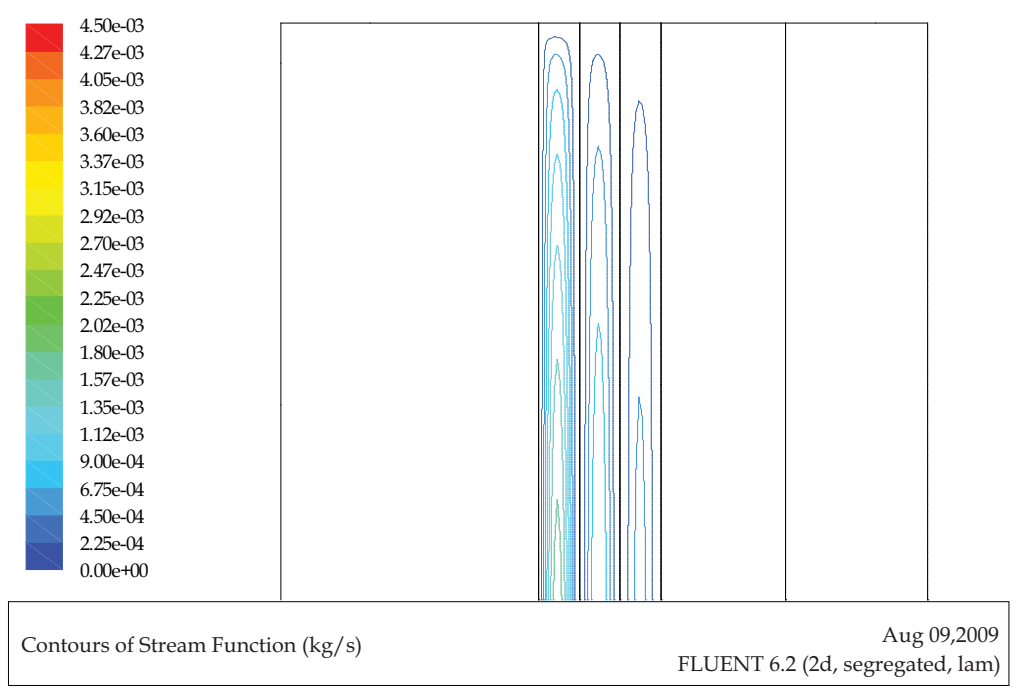

(c)

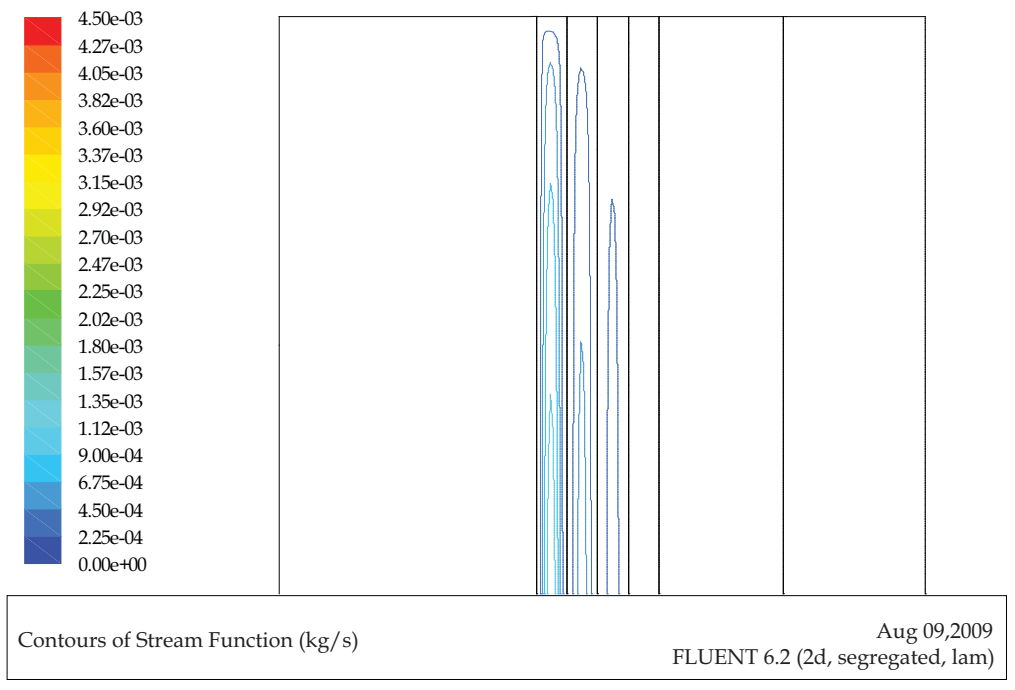

(d)

Fig. 5. (c) and (d) Streamlines in the air layer.

From these results it can be observed that when the velocity decreases, the heat transfer coefficient by convection is reduced and the overall heat losses decrease. This behavior is related to a boundary layer regime where the convection appears in the core region and the conduction is limited to a thin boundary layer near the walls (Ganguli et al., 2009). The Figures 5(a)-5(d) show the streamlines in the air layer, where the boundary layer regime with the unicellular flow pattern is identified. In each configuration we can see the flow 
patterns, where it is verified that the greater velocity is in the center of the cavity and this one falls when the partitions are added in the air layer.

Nevertheless, the best parameter to identify the insulating effect of the air layer is the heat transfer through the multi-layer wall. In the table 2 are shown eight configurations where the configuration 10 [4] shows more insulating capacity, reducing the heat losses. For this configuration each partition has a thickness near the optimal thickness. Then it is possible to deduce that continued adding partitions with thicknesses near the optimal one, the heat flow will fall significantly. This implies the increase in the total thickness of the wall, which is neither practical nor advisable economically.

Identifying the best configuration, the temperature profiles for an air layer of $10 \mathrm{~cm}$ and partitions from one to four are analyzed as shown in Figure 6. According to these profiles, for an air layer with a single division $(10 \mathrm{~cm})$ the core region does not have a temperature gradient, this behavior means that the heat transfer is controlled by the moving of the boundary layers near the walls with a flow in a laminar boundary layer regime. The heat transferred through the core is negligible. When the partitions in the air layer are placed, the temperature gradients appear indicating that the heat transfer through the multi-layer wall is present. Nevertheless, in configurations with partitions that have thicknesses bigger than the optimal, 10[2], the temperature profiles show small gradients, a condition similar to the air layer with a single division. When the air layer has three or four partitions, 10 [3] and 10[4], the temperature profile is linear which means that in the entire air layer the heat is transferred by conduction.

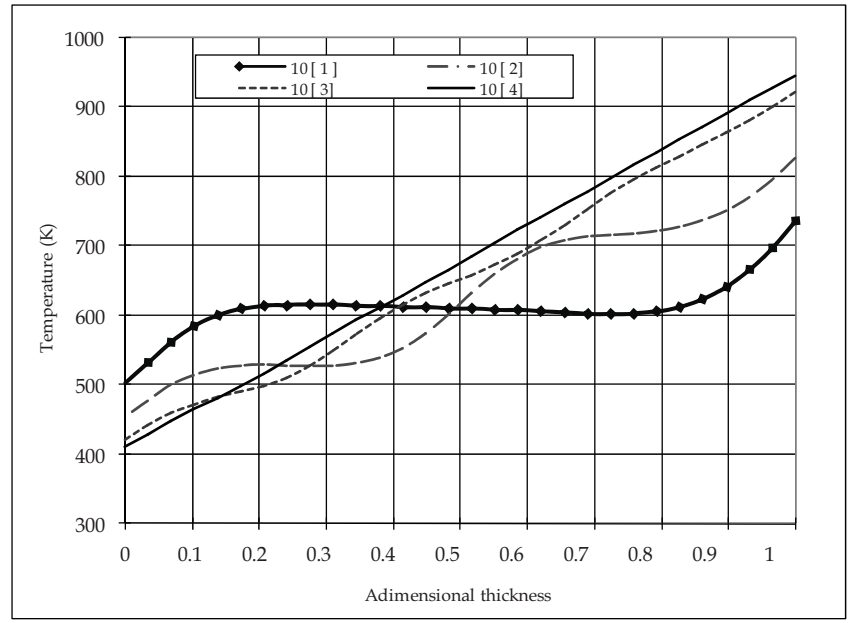

Fig. 6. Temperature profile in the air layer with different partitions.

The greatest temperature gradients appear in the air layer with four partitions, which confirms the importance to use an air layer with partitions that have thicknesses near the optimal. The Figures 7(a) to 7(d) show the temperature contours in the multi-layer wall, where it can be observed that an air layer without partitions, Figure 7(a), the core to be nearly isothermal and the heat transfer is controlled by the moving of the boundary layer near the walls (Ganguli et al., 2009). When the thickness decreases, Figures 7(b) and 7(c), a 
steep vertical temperature gradient near the wall is present confirming the existence of the cellular patterns and increasing the rate of the heat transfer through the air layer. With thickness near the optimal, Figure 7(d), there is a linear temperature distribution through the air layer and the heat transfer by conduction is dominant in that region of the thin cavity; however, convection becomes important at the top and bottom corners of the cavity (Ganguli et al., 2009).
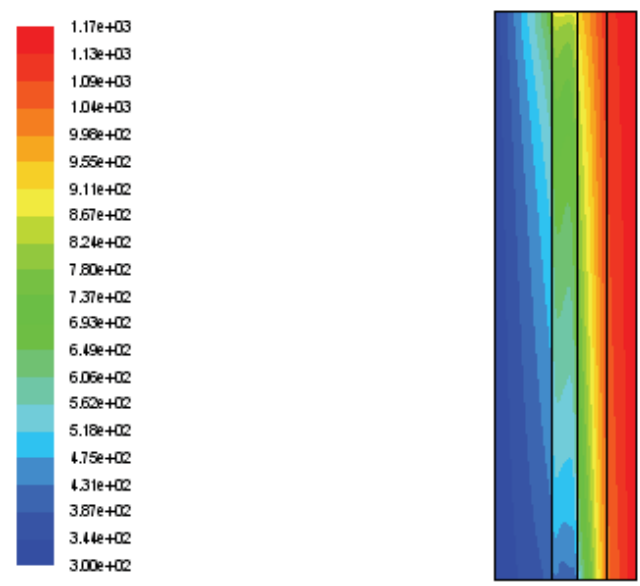

$\begin{array}{lr}\text { Coiburs of Static Temperature } 619 & \text { Alg 10, 2009 } \\ \end{array}$

(a)
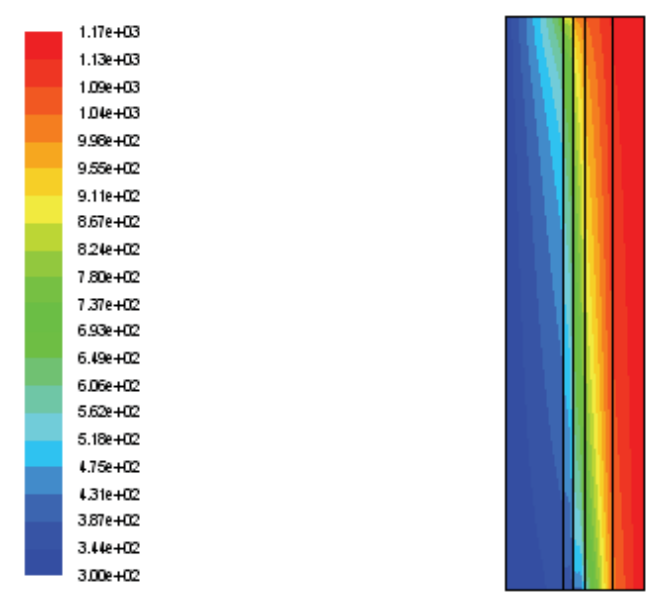

Coiburs of Static Temperature 0

(b)

Fig. 7. (a) and (b) Temperature contours in the multi-layer wall. 


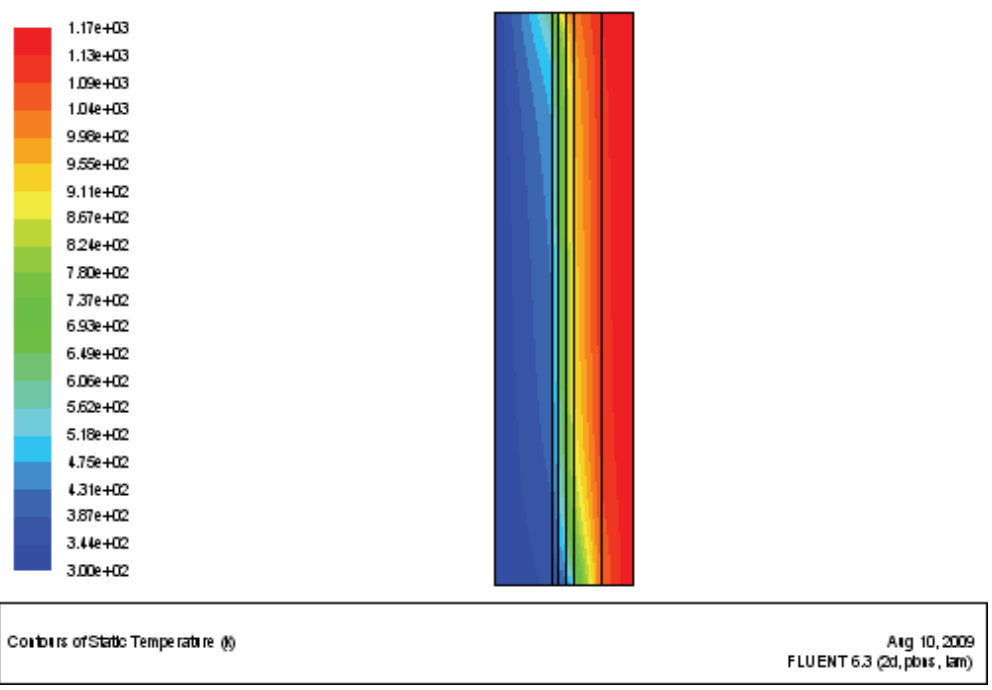

(c)

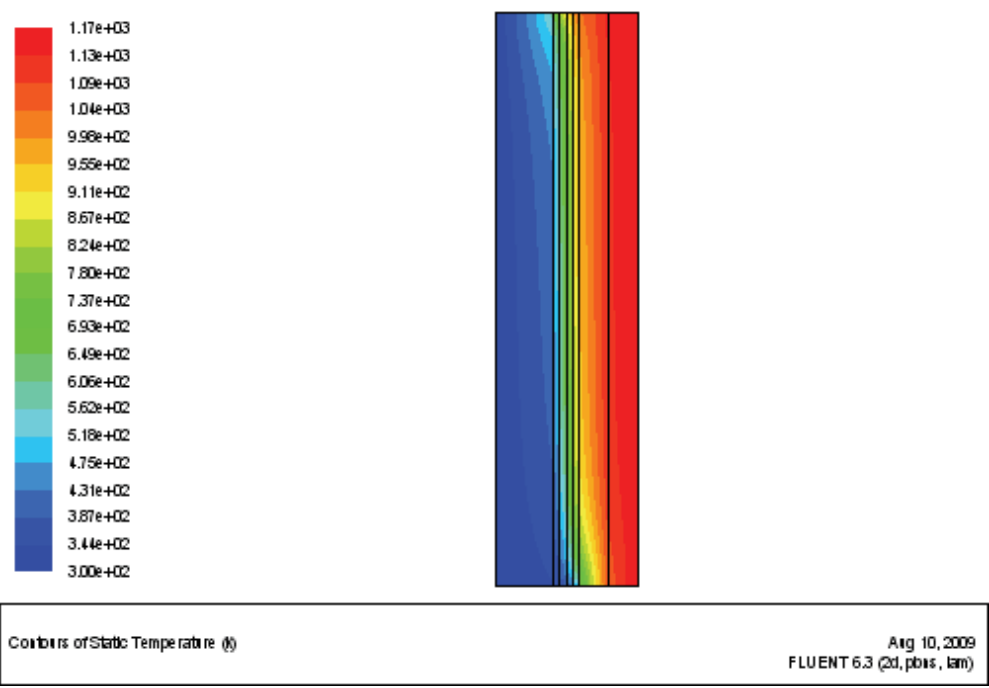

(d)

Fig. 7. (c) and (d) Temperature contours in the multi-layer wall.

\section{Conclusions}

In the study of the conjugate heat transfer in multi-layer walls, an optimal thickness was identified, also the number of partitions required to reduce the heat losses and obtain a greater insulating capability of the wall was determined. These walls were analyzed for operating conditions of the furnaces used to bake ceramic. 
An air layer with a thickness near $3 \mathrm{~cm}$ allows the minimal heat transfer loss; whereas the thickness of the other components of the multi-layer wall is constant since their size depends on the commercial dimensions of the materials used.

According to the temperature gradient through the multi-layer wall in a furnace, an air layer with vertical partitions reduces heat losses when the partitions have a thickness near the optimal one; this condition reduces the fuel consumption and the pollutant emissions. For example, the air layer of $10 \mathrm{~cm}$ with four partitions reduces about of $44 \%$ the heat flux through the wall, with respect to a single air layer with the same thickness.

The reduction of the heat flux from the furnace is considerable and the cost that implies to have an air layer with partitions is less than the cost of using a thermal insulator. In addition, when incorporating an air layer of $10 \mathrm{~cm}$ with four partitions, the total thickness of the multi-layer wall is $52 \mathrm{~cm}$, which is a typical thickness of the wall in the furnaces used for baking the ceramics. Also the energy savings make a significant contribution to the optimization of the baking process, reducing production costs.

\section{References}

Aydin O. (2000). Determination of optimum air-layer thickness in double-pane windows. Enegy and Building, 32, 303-308, ISSN: 0378-7788.

Aydin O. (2006). Conjugate heat transfer analysis of double pane windows. Building and Environment, 41, 109-116, ISSN: 0360-1323.

Balderas B. A.; Gallegos M. A.; Riesco Ávila J.M.; Violante Cruz C. \& Zaleta Aguilar A. (2007). Analysis of the conjugate heat transfer in a multi-layer wall: industrial application. Proceedings of the XIII International Annual Congress of the SOMIM. 869876, ISBN: 968-9173-02-2, México, September 2007, Durango, Dgo.

Darbandi M. \& Hosseinizadeh S. F. (2007). Numerical study of natural convection in vertical enclosures using a novel non-Boussinesq algorithm. Numerical Heat Transfer, Part A, 52, 849-873, ISSN: 1040-7782.

Department of Energy U.S.A. (Energy Efficiency and Renewable Energy) (2004). Waste heat reduction and recovery for improving furnace efficiency, productivity and emissions performance. Report DOE/GO-102004-1975, 1-8.

Fluent 6.2.16 (2007). User's Guide.

Ganguli A.; Pandit A. \& Joshi J. (2009). CFD simulation of the heat transfer in a twodimensional vertical enclosure. IChemE, 87, 711-727, ISSN: 0263-8762.

Incropera F. \& DeWitt D. (1996). Introduction to Heat Transfer, John Wiley, ISBN: 0-471-304581 , New York.

Lacarrière B.; Lartigueb B. \& Monchouxb F. (2003). Numerical study of heat transfer in a wall of vertically perforated bricks: influence of assembly method. Energy and Buildings, 35, 229-237, ISSN: 0378-7788.

Lacarrière B.; Trombe A. \& Monchoux F. (2006). Experimental unsteady characterization of heat transfer in a multi-layer wall including air layers-application to vertically perforated bricks. Energy and Buildings, 38, 232-237, ISSN: 0378-7788.

Patankar S.V. (1980). Numerical Heat Transfer and Fluid Flow, Hemisphere, ISBN: 0-07-0487405, New York. 
Samboua V.; Lartiguea B.; Monchouxa F. \& M. Adjb (2008). Theoretical and experimentalstudy of heat transfer through a vertical partitioned enclosure: application to the optimization of the thermal resistance. Applied Thermal Engineering, 28, 488-498, ISSN: 1359-4311.

Violante C. (2009). Analysis of the Conjugate Heat Transfer using CFD in Multi-Layer Walls for Brick Furnace. Thesis. 


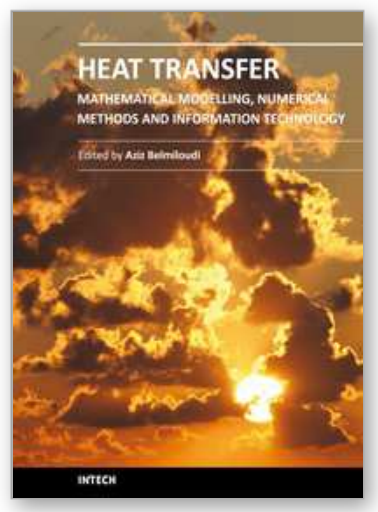

\section{Heat Transfer - Mathematical Modelling, Numerical Methods and Information Technology}

Edited by Prof. Aziz Belmiloudi

ISBN 978-953-307-550-1

Hard cover, 642 pages

Publisher InTech

Published online 14, February, 2011

Published in print edition February, 2011

Over the past few decades there has been a prolific increase in research and development in area of heat transfer, heat exchangers and their associated technologies. This book is a collection of current research in the above mentioned areas and describes modelling, numerical methods, simulation and information technology with modern ideas and methods to analyse and enhance heat transfer for single and multiphase systems. The topics considered include various basic concepts of heat transfer, the fundamental modes of heat transfer (namely conduction, convection and radiation), thermophysical properties, computational methodologies, control, stabilization and optimization problems, condensation, boiling and freezing, with many real-world problems and important modern applications. The book is divided in four sections : "Inverse, Stabilization and Optimization Problems", "Numerical Methods and Calculations", "Heat Transfer in Mini/Micro Systems", "Energy Transfer and Solid Materials", and each section discusses various issues, methods and applications in accordance with the subjects. The combination of fundamental approach with many important practical applications of current interest will make this book of interest to researchers, scientists, engineers and graduate students in many disciplines, who make use of mathematical modelling, inverse problems, implementation of recently developed numerical methods in this multidisciplinary field as well as to experimental and theoretical researchers in the field of heat and mass transfer.

\section{How to reference}

In order to correctly reference this scholarly work, feel free to copy and paste the following:

Armando Gallegos M., Christian Violante C., José A. Balderas B., Víctor H. Rangel H. and José M. Belman F. (2011). Analysis of the Conjugate Heat Transfer in a Multi-Layer Wall including an Air Layer, Heat Transfer Mathematical Modelling, Numerical Methods and Information Technology, Prof. Aziz Belmiloudi (Ed.), ISBN: 978-953-307-550-1, InTech, Available from: http://www.intechopen.com/books/heat-transfer-mathematicalmodelling-numerical-methods-and-information-technology/analysis-of-the-conjugate-heat-transfer-in-a-multilayer-wall-including-an-air-layer

\section{INTECH}

open science | open minds

\section{InTech Europe}

University Campus STeP Ri

Slavka Krautzeka 83/A

51000 Rijeka, Croatia

\section{InTech China}

Unit 405, Office Block, Hotel Equatorial Shanghai

No.65, Yan An Road (West), Shanghai, 200040, China

中国上海市延安西路65号上海国际贵都大饭店办公楼405单元 
Phone: +385 (51) 770447

Fax: +385 (51) 686166

www.intechopen.com
Phone: +86-21-62489820

Fax: +86-21-62489821 
(C) 2011 The Author(s). Licensee IntechOpen. This chapter is distributed under the terms of the Creative Commons Attribution-NonCommercialShareAlike-3.0 License, which permits use, distribution and reproduction for non-commercial purposes, provided the original is properly cited and derivative works building on this content are distributed under the same license. 